\title{
Ímpetos gestuais e saberes da gestão da classe na aula de educação física
}

http://dx.doi.org/10.11606/1807-5509201900010071

\author{
Sandra Barbosa da COSTA* \\ Marcílio de SOUSA JÚNIOR ${ }^{* * * * * * *}$ \\ Izabelle do Nascimento PEREIRA* \\ Pierre Normando GOMES-DA-SILVA* \\ ${ }^{*}$ Centro de \\ Ciências da Saúde \\ Universidade Federal \\ da Paraíba, João \\ Pessoa, PB, Brasil. \\ **Escola Superior \\ de Educação Física, \\ Universidade de \\ Pernambuco, Recife, \\ PE, Brasil. \\ ***Faculdade \\ de Educação, \\ Universidade de São \\ Paulo, São Paulo, SP \\ Brasil.
}

\section{Resumo}

0 objetivo deste seguinte estudo foi identificar como as atitudes pedagógicas estão relacionadas com os impetos gestuais e como estes são evidenciados no andar do professor durante a gestão da classe. Inicialmente destacamos a especificidade da Educação Física, em relação a sua sala de aula, que ocorre em diferentes espaços. Dentro deste espaço acontecem inúmeras situações a serem intermediadas pelo professor, dentre elas: a condução da turma para o espaço de aula; a organização dos materiais didático-pedagógico e dos alunos; e 0 ato de disciplinar, sobre os quais delimitaram nosso olhar analítico pela Labanálise. Tomamos a pesquisa qualitativa do tipo etnográfica a fim de analisar os modos de andar do professor durante a aula de Educação Física. Os sujeitos foram seis professores de Educação Física do Ensino Fundamental, da rede pública da cidade de João Pessoa/PB. Para observar as aulas utilizamos um protocolo de observação e registros no diário de campo. 0 andar dos professores para conduzir a turma apresentou-se, pela Labanálise, predominantemente com velocidade de passos moderados e poucas vezes rápidos, como foi o caso dos três grupos de professores G1, G2 e G3. Ao andar para organizar a aula, os grupos de professores apresentaram ênfase numa atitude controlada, ou seja, houve interrupção dos passos sempre que se fez necessário durante a aula. Ao andar para disciplinar, os professores do grupo G2 e G2 apresentaram ênfase numa atitude direta, ou seja, um andar determinado. Os três grupos de professores, desta forma, especificaram algumas particularidades em seu repertório individual de gestão da classe para organizar um ambiente propício para a aprendizagem.

Palavras-Chave: Professor; Andar; Labanálise; Gestos.

\section{Introdução}

As experiências profissionais desvelam características próprias em cada etapa da trajetória do professor e, dependendo dos anos de docência, estes professores podem apresentar estilos diferentes em seu modo de atuar nas escolas, incluindo sua gestualidade, e, subsequentemente, na gestão de suas classes. Com isso, nosso objetivo foi identificar como as atitudes pedagógicas estão relacionadas com os ímpetos gestuais e como estes são evidenciados no andar do professor durante a gestáo da classe. 
a trajetória profissional, podendo implicar em outras situações de movimento e intençôes pedagógicas dos docentes em suas salas de aulas.

O trabalho docente, portanto, é fruto do imbricamento entre as experiências profissionais e a carreira de professor. As condutas pedagógicas vão surgindo e sendo modificadas no decorrer de experiências vivenciadas pelos docentes. $\mathrm{O}$ trabalho docente tanto é espaço de exercício e ampliação de saberes, quanto de produção de saberes ${ }^{2}$.

À medida que os professores se relacionam com seus pares ${ }^{3}$ e com alguns elementos de seu ofício, eles tornam-se capazes de construírem novos caminhos, ocasionando mudanças em sua trajetória e apropriando-se de novos conhecimentos para sua ação docente. A Pedagogia da Corporeidade (PC) ${ }^{4}$ é uma teoria pedagógica que vem investigando a comunicação corporal, como um saber docente, chamando a atenção do professor para essa dimensão pedagógica. De modo que entender a gestualidade da ação docente como um saber produzido na interação ensino-aprendizagem foi decorrente dessa concepção de educação física. Como nosso foco no gesto do professor foi para o andar, entendemos que este também se faz, literalmente, em caminhos e trajetos de sua prática pedagógica e de seus saberes docentes.

No Brasil o debate em torno do saber docente ganha proeminência a partir de um texto de TARDIF publicado originalmente na Revista Teoria \& Educação, em 1991․ Entretanto, entre vários outros estudiosos que deram continuidade à discussão, focamos nosso olhar na gestão da classe a partir da contribuição de GAUTHIER et al. ${ }^{2}$, pois há uma preocupação com a natureza dos saberes docentes no ato pedagógico.

Os saberes docentes são um conjunto de conhecimentos advindos da relação entre trajetória de formação e exercício docente, que permitem uma ressignificação do ato e função pedagógicos. É, portanto, um saber plural, dinâmico, social, produto das relaçóes estabelecidas pelos sujeitos educacionais no contexto da educação.

Gauthier et al. ${ }^{2}$ reconhecem dois grupos de funçóes pedagógicas: o da gestão da matéria, que aborda o conhecimento objeto da educação, no qual está o planejamento, o ensino e a avaliação e o da gestão da classe, que foca os sujeitos no ambiente da educação (a turma), no qual estão as normas e disposiçôes para organizar um ambiente propício para a aprendizagem.

Para os autores ${ }^{2}$ os saberes docentes se estruturam em diferentes tipos: os disciplinares, referentes às áreas de conhecimento, ao que se ensina; os curriculares, ligados aos programas de conteúdos elaborados por entes oficiais do ensino; os da tradição pedagógica, relacionados ao ato de ensinar; os das ciências da educação que dão fundamentos teóricos à educação; os experienciais, que são produzidos pelo docente no ato de ensinar; e os da ação pedagógica, ligados aos saberes experienciais que são validados cientificamente na comunidade acadêmica. Segundo GUIMARÁEs $^{6}$ os saberes experienciais se entrecruzam e diante de diferentes funçôes pedagógicas, se estruturam em saberes organizativos, cognitivos e afetivos, conforme Figuras 1 e 2.

Os saberes experienciais organizativos ${ }^{6}$ são aqueles mobilizados pelo docente com vistas à organização do trabalho como um todo. Já os cognitivos procuram atender à sistematização do conhecimento socialmente valorizado para formação do aluno/a. E os afetivos são aqueles que envolvem as subjetividades e expectativas de sujeitos sociais com vistas à recepção dos alunos/as, para sentirem-se bem, e são ligados ao incentivo e estímulo.

Enfim, o trabalho docente, o modo de atuar nas escolas, as condutas pedagógicas, mobiliza/ produzem saberes e entre esses os experienciais organizativos, especialmente em interação com a função pedagógica de gestão da classe, o que exige do professor capacidades/habilidades/atitudes para lidar com diferentes situações e intenções, sejam elas genéricas à escola como um todo ou mesmo particulares a uma disciplina específica. Foi nessa compreensão que nos aproximamos para analisar os saberes organizativos na gestáo da classe em educação física, especialmente a gestualidade do professor, observando especificamente seus ímpetos nos diferentes espaços e situaçóes pedagógicas.

Inicialmente destacamos a especificidade da EF, em relação a sua sala de aula, que ocorre em diferentes espaços, tais como pátio, campo, quadra ou outro espaço próprio à movimentação, com delimitações muito maiores do que uma sala de aula comum.

Dentro deste espaço acontecem inúmeras situaçóes a serem intermediadas pelo professor, dentre elas: a condução da turma para o espaço de aula; a organização dos materiais didáticopedagógico e dos alunos; e o ato de disciplinar, sobre os quais delimitaram nosso olhar analítico pela labanálise ${ }^{7}$. Em cada situação há intenções pedagógicas adotadas pelo docente. Essas situações e intenções manifestam-se de formas diferentes, já que cada docente e cada turma carregam sua própria experiência e com isso uma maneira própria de agir em cada momento de aula. 


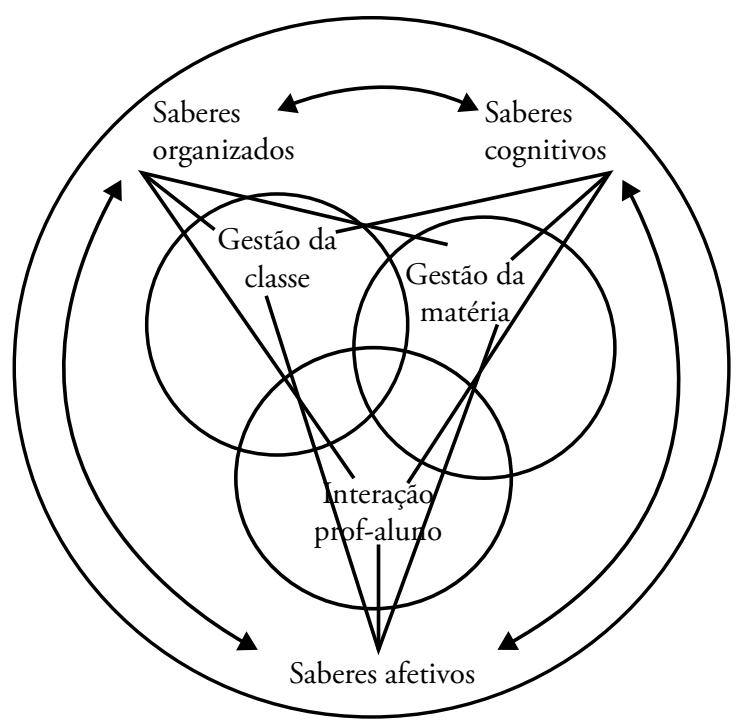

FIGURA 1 - Articulação entre os saberes da experiência e as funções pedagógicas.

Fonte: Guimarães ${ }^{6}$.

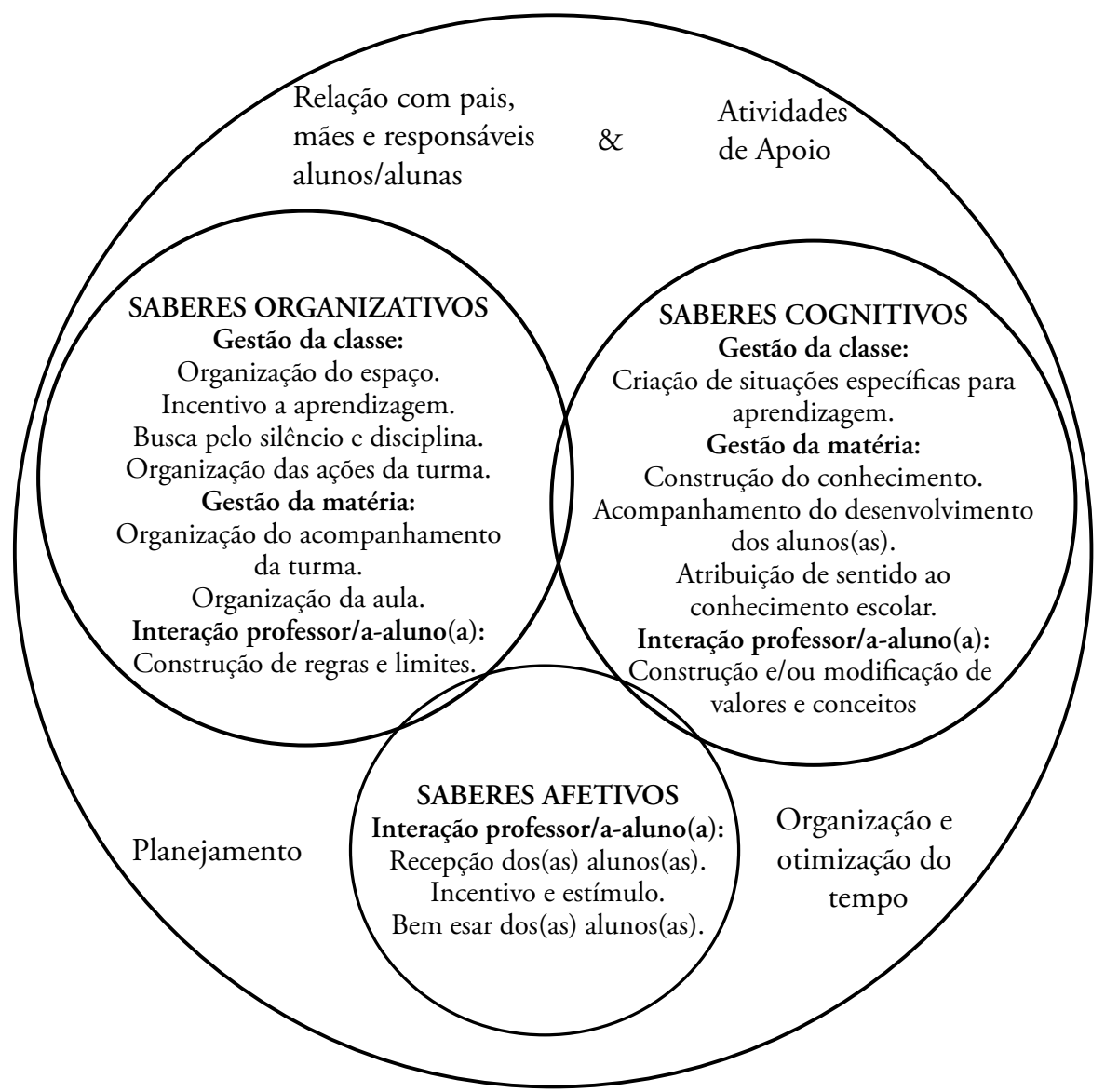

FIGURA 2 - Dinâmica dos saberes no trabalho docente.

Fonte: Guimarães ${ }^{6}$.

Gomes-DA-Silva et al. ${ }^{8}$ afirmam que o espaço da educação física deve se constituir num ambiente enriquecido, apresentando oportunidades para se vivenciar outras aprendizagens, próprias da movimentação. Pois o pivô da aprendizagem, nessa abordagem, está na própria situação de movimento. 
Freire e SCAGLIa ${ }^{9}$ já haviam rompido com a ideia de que só se aprende em espaços delimitados pelas carteiras e no silêncio de uma sala de aula comum, mas também se aprende com a bola em movimentaçâo. $\mathrm{O}$ documento da Base Nacional Comum Curricular ${ }^{10}$ afirma que a cultura corporal de movimento propicia ao sujeito o acesso a uma dimensão de conhecimento e de experiências à qual ele não teria acesso de outro modo. Nessa compreensão, destacamos a gestualidade do professor de educação física, especialmente seu andar em aula como componente do saber experiencial organizativo da gestão da classe.

A prática pedagógica na Educação Física escolar requer muito dos gestos e movimentos não só dos alunos, mas também dos professores. De acordo com GoMES-DA-SiLva et al. ${ }^{11}$, a gestualidade é uma linguagem cifrada que necessita ser mais bem compreendida. Numa abordagem semiótica da Educaçáo Física ${ }^{11}$ indicam que a semiótica permite lançar novos olhares epistêmicos para a análise e intervenção na Educação Física, permitindo: compreender todas as suas manifestaçóes como expressivas, significativas e comunicativas. O termo semiótica, em sua acepçáo moderna, foi elaborado por Charles Sanders Peirce (1839-1914). De acordo com SANTAELLA ${ }^{12}$, para Peirce toda e qualquer produção, realização e expressão humana é uma questão semiótica. O signo da comunicação corporal diz dos gestos observáveis, sendo uma rede de comunicaçáo desenvolvida nas posiçóes, atitudes e deslocamentos corporais. A atitude refere-se ao posicionamento do indivíduo frente as suas experiências de aprendizagem.

Neste estudo, o gesto observado foi o ato do andar do professor, ou seja, seus deslocamentos realizados na aula foram tomados como signos e sendo decifrados pelo método Análise Laban de Movimento ou simplesmente Labanálise ${ }^{7}$, porque nele, as dinâmicas do movimento são descritas com ênfase em seus aspectos qualitativos em termos de como cada uma dessas açóes é executada, ou seja, rapidamente, levemente, diretamente, livremente, como num andar vagaroso ${ }^{13}$.

O trabalho de Mauss ${ }^{14}$, já em 1935, vislumbrou o fenômeno do andar em sua complexidade cultural e, portanto, como fenômeno de linguagem. Nesse contexto, compreende-se que o gesto do andar é uma linguagem simbólica que expressa diversas situaçōes pedagógicas do professor. Assim, formulamos a nossa questão problema:

Como as atitudes pedagógicas estão relacionadas com os ímpetos gestuais e como estes são evidenciados no andar do professor durante a gestáo da classe?

\section{Método}

Tomamos a pesquisa qualitativa do tipo etnográfica a fim de analisar os modos de andar do professor durante a aula de Educação Física. Os sujeitos foram seis professores de Educação Física do Ensino Fundamental, da rede pública da cidade de João Pessoa/ PB. A escolha foi intencional e combinaram-se três critérios pré-definidos: tempo de atuação profissional na área da Educação Física Escolar, professores de ambos os sexos e um professor para cada escola.

Foram constituídos três grupos de dois professores de educação física de ambos os sexos: o primeiro grupo (G1) estava iniciando a trajetória profissional e atuando há, no máximo, cinco anos; o segundo grupo (G2), estava atuando há mais de dez anos e o terceiro grupo (G3), estava atuando há mais de vinte anos.

Essa distribuiçáo dos grupos destacou o contexto das experiências profissionais. Utilizamos a observação participante e entrevista semiestruturada ${ }^{15}$. Foram observadas sete aulas de cada professor, totalizando 42 observações de aulas de Educação Física em escolas públicas. Observamos uma aula por semana, de cada professor, com o objetivo de uma maior permanência no campo de pesquisa a fim de descrever o fenômeno desvelando-se em sua complexidade, pois o ato de andar é táo comum que para perceber suas especificidades nos modos de andar de cada professor necessitávamos de mais tempo e de uma maior diversidade de idade, de gênero e de tempo de atuação profissional.

Em cada uma das sete observaçôes, foi utilizado um protocolo de observação criado por $\operatorname{CosTA}{ }^{16}$ para o registro dos modos de andar durante a aula. Além do protocolo de observação, outras açóes da aula foram registradas no diário de campo. $\mathrm{O}$ ato do andar é um gesto básico humano e, sendo analisado na atuação do professor em diferentes momentos da carreira, está implicado em suas situaçóes e intençóes pedagógicas nas aulas de educação física.

Utilizando-nos da teoria de Laban, que segundo Mommensohn e Petrella ${ }^{17}$, foi um dos grandes pensadores do movimento humano e de seu vasto campo de expressão identificamos os fatores: fluxo, espaço, peso e tempo no andar do professor durante sua prática docente. Por estes fatores analisamos os 
modos de andar como signos das atitudes pedagógicas do professor, durante sua gestão da classe.

Assim, pretendeu-se verificar quais foram às qualidades atitudinais e os ímpetos da ação docente que se manifestaram durante $o$ ato do andar dos professores. Para LacAVA ${ }^{18}$, o modo de andar do indivíduo indica uma intenção da ação, e, por exemplo, podemos identificar quem está chegando em casa pela forma como se movimenta para abrir a porta ou pela forma como realiza seus passos ao andar, mesmo estando fora do campo de visão. A forma como combina os fatores do movimento para as açóes de abrir a porta ou andar está impressa em sua personalidade que se manifesta, exterioriza-se, mediante o movimento, o mover-se.

Para $\operatorname{LABAN}^{7}$, o fator fluxo refere-se à qualidade da tensão muscular usada para deixar fluir o movimento (fluxo livre) ou para restringi-lo (fluxo controlado); o fator espaço refere-se à qualidade de atençáo do indivíduo no seu ambiente ao mover-se. Ele pode ter sua atenção concentrada em um único ponto (foco direto) ou ter sua atenção expandida por vários pontos (foco indireto ou multifoco); o fator peso refere-se à qualidade da força utilizada pelo corpo ao mover-se, mobilizando seu peso para empurrar, puxar ou tocar em outro corpo, podendo ser forte ou leve; o fator tempo indica uma variação na qualidade de velocidade do movimento, que se torna gradualmente mais rápido ou mais lento. Nesse contexto, na Análise Laban de Movimento, estudar as qualidades de um movimento significa compreender como esse movimento é realizado ${ }^{19}$.

Peso, espaço, tempo e fluxo, para $\mathrm{LABAN}^{7}$, são os fatores perante os quais a pessoa adota uma atitude definida. $\mathrm{O}$ conjunto das várias atitudes poderia ser a seguinte: uma atitude complacente ou enérgica, quanto ao fator peso; uma atitude direta ou indireta, quanto ao fator espaço; uma atitude rápida ou lenta, frente ao fator tempo; uma atitude livre ou controlada, em relaçáo ao fator fluxo. Quando combinadas a atitude direta (Espaço) e rápida (Tempo) temos o surgimento de uma atitude lutante.

Segundo $\operatorname{LABAN}^{7}$, há inúmeras possibilidades de combinações entre os quatro fatores revelando a riqueza expressiva do movimento e, quando ocorre uma combinação de três fatores de movimento, a expressão é mais comunicativa. Podemos dizer que a atitude passa a ter traços impetuosos, veementes, onde impulsos e efusóes mobilizam saberes e produzem ímpetos. Desse modo, no gesto em que o fator fluxo se mantém latente, ou seja, sem predominância na ação gestual e, apenas os fatores peso/tempolespaço operam com predominância, considera-se como impeto de ação; quando é o fator peso que se encontra latente, sem predominância, e, apenas os fatores fluxo/tempolespaço operam com predominância considera-se como ímpeto de visão; quando é o fator tempo que se encontra latente, e, apenas os fatores fluxo/pesolespaço operam com predominância considera-se como ímpeto de encanto; e, quando é o fator Espaço que se encontra latente e, apenas os fatores fluxo/tempo/peso operam com predominância considera-se como ímpeto de paixão. Ainda, diante desse contexto, é importante destacar que, não são todos os fatores do movimento que são sempre significativos e que predominam numa determinada expressão gestual, pois conforme o modo de se combinarem produzem gradaçóes particulares de ação, ou seja, atitudes e ímpetos diferenciados ${ }^{7}$. O QUADRO 1 demonstra como estão definidas as qualidades, atitudes e os ímpetos pela análise Laban de movimento.

QUADRO 1 - Fatores de movimento com suas respectivas qualidades, atitudes e ímpetos no ato comunicativo

\begin{tabular}{|l|l|l|}
\hline $\begin{array}{l}\text { Qualidades dos fatores de } \\
\text { movimento }\end{array}$ & $\begin{array}{l}\text { Fatores de movimento e suas respecti- } \\
\text { vas atitudes }\end{array}$ & $\begin{array}{l}\text { Fatores de movimento e } \\
\text { seus respectivos ímpetos }\end{array}$ \\
\hline $\begin{array}{l}\text { Fator peso: } \\
\text { refere-se à força utilizada pelo corpo ao } \\
\text { mover-se podendo ser: forte ou leve. }\end{array}$ & $\begin{array}{l}\text { No fator Peso, observam-se duas atitudes: } \\
\text { Atitude Complacente (possui qualidades } \\
\text { Leves) } \\
\text { Atitude Enérgica (possui qualidades } \\
\text { Fortes) }\end{array}$ & $\begin{array}{l}\text { No Ímpeto de Visáo } \\
\text { observa-se: } \\
\text { (-) Peso e, } \\
+ \text { Tempo + Espaço + } \\
\text { Fluxo. }\end{array}$ \\
\hline $\begin{array}{l}\text { Fator espaço: } \\
\text { refere-se à atenção do indivíduo } \\
\text { concentrada em um único ponto (foco } \\
\text { direto) ou expandida por vários pontos } \\
\text { (foco indireto ou multifoco). }\end{array}$ & $\begin{array}{l}\text { No fator Espaço observam-se duas } \\
\text { atitudes: } \\
\text { Atitude Direta (possui qualidades com } \\
\text { foco direto); } \\
\text { Atitude Indireta (qualidades com foco } \\
\text { indireto) }\end{array}$ & $\begin{array}{l}\text { No Ímpeto de Paixão } \\
\text { observa-se: } \\
\text { (-) Espaço e, } \\
+ \text { Peso + Tempo + Fluxo. }\end{array}$ \\
\hline
\end{tabular}


Continuação

QUADRO 1 - Fatores de movimento com suas respectivas qualidades, atitudes e ímpetos no ato comunicativo

\begin{tabular}{|l|l|l|}
\hline $\begin{array}{l}\text { Qualidades dos fatores de } \\
\text { movimento }\end{array}$ & $\begin{array}{l}\text { Fatores de movimento e suas respecti- } \\
\text { vas atitudes }\end{array}$ & $\begin{array}{l}\text { Fatores de movimento e } \\
\text { seus respectivos ímpetos }\end{array}$ \\
\hline $\begin{array}{l}\text { Fator tempo: } \\
\text { refere-se à velocidade do movimento, } \\
\text { que se torna: mais rápido ou mais lento. }\end{array}$ & $\begin{array}{l}\text { No fator Tempo observam-se duas atitudes: } \\
\text { Atitude Rápida (qualidades de } \\
\text { movimento rápida) } \\
\text { Atitude Lenta (qualidades de } \\
\text { movimentação lenta) }\end{array}$ & $\begin{array}{l}\text { No Ímpeto de Encanto } \\
\text { observa-se: } \\
\text { (-) Tempo e, } \\
+ \text { Peso + Espaço + Fluxo. }\end{array}$ \\
\hline $\begin{array}{l}\text { Fator fluxo: } \\
\text { refere-se à tensão muscular para: deixar } \\
\text { fluir o movimento (fluxo livre) ou para } \\
\text { restringi-lo (fluxo controlado). }\end{array}$ & $\begin{array}{l}\text { No fator Fluxo observam-se duas atitudes: } \\
\text { Atitude Livre (possui qualidades de } \\
\text { fluxo livre) } \\
\text { Atitude Controlada (possui fluxo } \\
\text { controlado) }\end{array}$ & $\begin{array}{l}\text { No Ímpeto de Ação } \\
\text { observa-se: } \\
\text { (-) Fluxo e, } \\
+ \text { Peso + Tempo + Espaço. }\end{array}$ \\
\hline
\end{tabular}

Fonte: Laban?.

Observa-se no QUADRO 1 que para cada fator de movimento há uma dupla possibilidade de expressão com uma graduação contínua entre dois polos: peso forte-leve; espaço direto-indireto; tempo rápido-lento; fluxo livre-controlado. LABAN ${ }^{7}$ busca nos fatores de movimento expressar a integração dos opostos na qual o espaço interno do indivíduo e o externo estão intimamente relacionados. Ou seja, a maneira pela qual me movo no meu espaço interno (decidida, lutante, hesitante, afetuosa, raivosa) determina o modo como ocupo ou não o espaço externo. Objetivamente, há inúmeras combinações entre os fatores revelando a riqueza expressiva tanto de atitudes quanto de ímpetos de comunicação gestual ${ }^{20}$. Este estudo atendeu às exigências éticas da pesquisa científica através da aprovação do projeto pelo comitê de ética da Universidade Federal da Paraíba sob o número 0037 . A solicitaçáo da assinatura do termo de consentimento livre esclarecido foi entregue após haver a concordância do sujeito na participação do estudo.

\section{Resultados}

Os resultados do estudo descrevem inicialmente os modos de andar dos grupos de professores a partir das situações pedagógicas de: condução da turma, organização da aula e disciplina dos alunos, conforme Costa $^{16}$. Estamos interessados em saber como o andar foi realizado pela labanálise ${ }^{7}$.

QUADRO 2 - Situações encontradas na gestão da classe nas aulas de educação física

\begin{tabular}{l} 
1. Condução da turma: \\
Desde a chegada do professor na escola, na intenção de iniciar sua aula, até o encontro com a turma em sala de \\
aula, a fim de conduzi-los até o espaço da quadra para iniciar a prática de Educação Física Escolar. \\
\hline $\begin{array}{l}\text { 2. Organização da aula: } \\
\text { Nas relaçóes de distribuição dos materiais didáticos no espaço da aula, na explicaçáo e no acompanhamento das } \\
\text { atividades desenvolvidas pelos alunos durante a aula. }\end{array}$ \\
$\begin{array}{l}\text { 3. Disciplina dos alunos: } \\
\text { Diante de uma situação de indisciplina, a reação disciplinar do professor para retomar o bom funcionamento da aula. }\end{array}$
\end{tabular}

Fonte: $\operatorname{Costa}^{16}$. 


\section{O andar dos professores na situaçáo de conduçáo da turma}

Grupo G1: Ao andar para conduzir a turma em fileiras, o grupo de professores G1 que estavam atuando há, no máximo, cinco anos, ajustou a velocidade de seus passos a partir das passadas de seus alunos.

$\mathrm{O}$ primeiro aluno da fileira era conduzido pelas máos, lado a lado da professora G1, de 25 anos de idade. Seus passos na condução dos alunos foram de velocidade moderada e lenta, referente ao fator tempo e, realizou passos direto, referente ao fator espaço, ou seja, a professora andou diretamente ao local da realização da sua aula prática. $O$ fator fluxo do seu andar foi livre, pois os passos da professora seguiam livremente até chegar ao local de aula, não interrompendo seu caminhar no trajeto da sala até a quadra.

Ao andar para conduzir a turma o professor G1, 25 anos de idade, se posicionava lado a lado dos alunos. Tocava levemente na cabeça dos alunos. Algumas vezes andou na frente dos alunos, segurando os materiais didáticos. O seu andar fluiu livremente até a quadra. Ao andar para conduzir a turma, este apresentou passos moderados e lentos, referentes ao fator tempo e passos diretos, referente ao fator espaço.

Grupo G2: Ao andar para conduzir a turma em fileiras o grupo G2, que estava atuando há mais de dez anos, também como ocorreu no G1, ajustou a velocidade de seus passos a partir das passadas de seus alunos.

A professora G2, 41 anos de idade, ao conduzir a turma para o local de aula andou próxima à turma, colocando-se, algumas vezes, lado a lado, e, outras vezes, posicionando-se um pouco mais a frente dos alunos. Quando andou ao lado dos alunos, seus passos foram ritmados com as passadas dos alunos; mas, quando andou na frente, seus passos foram de moderados a rápidos, referentes ao fator tempo. Conduzindo a turma, ela andou segurando a mão do aluno que ora se encontrava ao seu lado. Na maioria das aulas, ao andar para conduzir, a professora G2 deu passadas firmes e enérgicas, referentes ao fator peso, e passos diretos, referentes ao fator espaço.

O professor G2, 41 anos de idade, ao andar para conduzir apresentou velocidade lenta, referente ao fator tempo, com passadas lado a lado dos alunos e com o toque leve nas costas ou ombros dos alunos, referente ao fator peso pela labanálise ${ }^{7}$. $\mathrm{O}$ andar para conduzir do professor também aconteceu sempre ao final da aula, quando levava os alunos direto, fator espaço referente a labanálise, de volta à sala de aula.
Grupo G3: Ao andar para conduzir a turma em fileiras o grupo G3, que estava atuando há mais de vinte anos, também como ocorreu no G1 e G2, ajustou a velocidade de seus passos a partir das passadas de seus alunos, caminhando lado a lado.

A professora G3, 54 anos de idade, andou com dificuldades devido às dores sentidas em seus pés e joelhos. Seus passos na condução dos alunos foram de velocidade lenta, referente ao fator tempo e, realizou passos direto, referente ao fator espaço ao caminhar direto para o campo.

O professor G3, 50 anos de idade, manteve contato corporal leve ao andar para conduzir não ocorreu em todas as aulas como observado nos demais professores. Seus passos apresentaram-se com tempo rápido e direto ao andar em direção ao campo. Algumas vezes, o professor andou na frente da turma e, outras vezes, no meio da turma ou mesmo atrás da turma. Os demais grupos de professores geralmente, no andar para conduzir, andaram à frente ou ao lado dos alunos e de mãos dadas.

\section{$O$ andar dos professores na situaçáo de organizaçáo da aula}

Grupo G1: Ao andar para organizar a aula, o grupo de professores $\mathrm{G} 1$ andou em várias direçóes como em linhas retas e curvas e, para trás e para frente.

A professora do grupo G1 teve dificuldades para organizar a aula devido ao comportamento indisciplinar da sua turma. Necessitou interromper frequentemente o seu andar devido aos atos de indisciplina de seus alunos, o que caracterizou um fator de fluxo ora controlado e ora livre. Ou seja, seus passos ficavam ziguezagueando no ambiente para tentar explicar as atividades aos alunos e desse modo o seu andar multifocado em várias direçóes da sala, caracterizou o fator espaço com qualidade indireta.

Quanto à organização da aula o professor G1, andou com passos multifocados em várias direçóes, referente ao fator espaço, andou para frente e para trás, observando o jogo dos alunos. Algumas vezes andou mais rápido e, outras vezes, mais lento referente ao fator tempo. A velocidade de seus passos também se apresentou moderado e lento, referente ao fator tempo.

Grupo G2: Ao andar para organizar a aula o grupo $\mathrm{G} 2$, realizou passadas predominantemente diretas e focadas nas direçóes dos passos dos seus alunos, ou seja, uma atenção multifocada, referente ao fator espaço. 
A professora G2 andou lado a lado dos alunos, tocando-os levemente nos ombros durante as atividades. Seus passos foram predominantemente rápidos, referente ao fator tempo e direto, referente ao fator espaço.

O professor G2 imprimiu um ritmo de moderado a lento ao andar para organizar a aula. Seu andar fluiu em diferentes direçôes da quadra. Andou para frente e para trás, para os lados e em linhas curvas. $\mathrm{O}$ fator espaço no andar do professor que estava em constante deslocamento apresentou qualidades diretas e indiretas e uma atenção multifocada em todos seus alunos. Nesse contexto, a qualidade do foco direto e indireto no andar do professor teve um ponto determinado, que foi o aluno.

Grupo G3: Ao andar para organizar a aula o grupo G3, não apresentou alteraçóes nas velocidades dos passos ao andar, qualidade do fator tempo pela labanálise, em relação aos demais grupos. Desse modo, o andar do grupo G3 que, possui uma longa trajetória de atuaçáo, mais de vinte anos na mesma escola, não apresentou ênfase no fator tempo.

A professora G3 apresentou passos predominantemente lentos, referente ao fator tempo. No momento de explicar as atividades aos alunos, mantinha-se de pé, com pouco deslocamento; seus passos foram de comprimentos curtos e de velocidade lenta.

O professor G3 andou com passos de comprimentos largos e rápidos, referente ao fator tempo. Nossos dados demonstraram que o andar do professor G3 é diferente do andar da professora $\mathrm{G} 3$ no que diz respeito à largura dos passos, ou seja, os passos do professor apresentaram um comprimento maior do que os passos da professora.

\section{$O$ andar dos professores na situaçáo de disciplinar os alunos}

Grupo G1: Ao andar para disciplinar os alunos em sala de aula o grupo G1, atuando há no máximo cinco anos, apresentou alteraçóes nas velocidades dos passos ao andar, qualidade do fator tempo e andou em várias direçôes com passos multifocados sempre diante de uma situação de indisciplina.

A professora G1 ao andar para disciplinar seus alunos durante o desenvolvimento da aula andou em várias direçóes com passos diretos e indiretos, ou seja, multifocados, referente ao fator espaço para ter o controle da aula. Devido à grande frequência de interrupção de seus passos, em algumas aulas, o seu modo de andar para disciplinar na prática docente apresentou passos de comprimento curtos, ou seja, passos pequenos e, algumas vezes rápidos ou desacelerados, referente ao fator tempo.

Ao andar para disciplinar o professor G1 apresentouse com passos rápidos, referente ao fator tempo e fluência controlada, além de andar constantemente para trás, o que o mantinha com o olhar focado diretamente nos alunos demonstrando uma atitude direta para discipliná-los caso fosse necessário. Seus passos foram preferencialmente de peso leve para disciplinar os alunos.

Grupo G2: Ao andar para disciplinar os alunos o grupo G2, atuando há mais de dez anos, andou em várias direçóes com passos multifocados sempre diante de uma situação de indisciplina dos alunos.

A professora $\mathrm{G} 2$ andou com passos rápidos e em várias direçôes apresentando passos multifocados para corrigir seus alunos. No aspecto disciplinar, utilizouse do diálogo, para que seus alunos respeitassem as regras do jogo e não aceitou que os alunos ficassem fora das atividades.

O professor G2 andou todo o tempo da aula com o olhar focado nos alunos. Durante a aula, andou predominantemente moderadamente e poucas vezes mais rápido, referente ao fator tempo, principalmente para recolocar alguns alunos, que se retiravam das atividades, de volta aos jogos. O fator espaço mostrouse com alternância entre o foco direto e multifocado. Seus alunos apresentaram um bom comportamento durante as sete aulas observadas.

Grupo G3: O grupo G3 no ato de disciplinar os alunos, apresentou uma dinâmica diferente em relação aos demais grupos. Pois, o modo de andar desses professores não sofreu alteraçóes significativas quanto à qualidade de velocidade dos passos e passadas, referente ao fator tempo, ou seja, o movimento expressivo no andar, tanto da professora quanto do professor para este grupo G3 apresentou-se, num compasso predominantemente contínuo e sem alteraçôes de velocidades nas passadas para disciplinar os alunos, ou seja, sem ênfase no fator tempo pela labanálise. Assim, a professora manteve predominantemente seus passos lentos enquanto que o professor andou preferencialmente rápido durante aula. $\mathrm{O}$ modo de andar da professora quanto do professor alternou-se com passadas entre diretas e indiretas, ou seja, um modo de andar multifocado no fator espaço, com passos em várias direçóes da aula para disciplinar seus alunos. Houve fluência livre de seus passos durante todas as aulas desses professores com atuação superior a vinte anos de docência. O Quadro 3 apresenta uma síntese dos resultados referente as qualidades, ímpetos e atitudes dos professores que foram desvelados em 
campo neste estudo a partir do ato do andar durante gestão da classe.

Conforme o QUADRO 3, o nosso estudo apresentou quatro ímpetos na gestão da classe de educação física e quatro atitudes na relação com os fatores de movimento ${ }^{7}$ : ímpetos de visão: deu-se quando o fator fluxo esteve sem predominância no andar dos professores; ímpetos de ação: deu-se quando o fator peso esteve sem predominância no andar dos professores; ímpetos de encanto: deu-se quando o fator tempo esteve sem predominância no andar dos professores; ímpetos de paixão: deu-se quando o fator espaço esteve sem predominância no andar dos professores.

QUADRO 3 - Relações da gestão da classe referente às atitudes gestuais e os ímpetos de comunicação prevalentes no andar do professor de educação física

\begin{tabular}{|c|c|c|}
\hline Situaçôes de gestão da classe & $\begin{array}{l}\text { Ímpetos de comunicaçáo no } \\
\text { andar dos professores }\end{array}$ & $\begin{array}{l}\text { Atitudes pedagógicas dos } \\
\text { professores }\end{array}$ \\
\hline $\mathrm{Na}$ condução da turma & $\begin{array}{l}\text { Prevalência do } \\
\text { Împeto de Açáo nos grupos: } \\
\text { G1 G2 G3 }\end{array}$ & $\begin{array}{l}\text { Prevalência da } \\
\text { Atitude Complacente em } \\
\text { G1 G2 G3 }\end{array}$ \\
\hline Na organização da aula & $\begin{array}{l}\text { Prevalência do } \\
\text { Împeto de Visão nos grupos: } \\
\text { G1 G2 G3 }\end{array}$ & $\begin{array}{l}\text { Prevalência da } \\
\text { Atitude Enérgica em } \\
\text { G1 G2 G3 }\end{array}$ \\
\hline $\mathrm{Na}$ disciplina dos alunos & $\begin{array}{l}\text { Prevalência do } \\
\text { Ímpeto de Visão nos grupos: } \\
\text { G1 G2 } \\
\text { Prevalência dos } \\
\text { Ímpetos de Paixão e de Encanto } \\
\text { Apenas no G3 }\end{array}$ & $\begin{array}{l}\text { Prevalência da } \\
\text { Atitude Direta em } \\
\text { G1 G2 } \\
\text { E, prevalência da Atitude Lutante e } \\
\text { Indireta/flexível em G3 }\end{array}$ \\
\hline
\end{tabular}

Fonte: Costa $^{16}$.

Ainda no QUADRO 3 pode-se identificar as quatro atitudes desveladas neste estudo a partir da relação com os fatores de movimento ${ }^{7}$ no andar dos professores: atitude complacente: deu-se quando as qualidades do fator peso foram predominantemente leves, num andar com passadas suaves; atitude enérgica: deu-se quando as qualidades do fator peso foram predominantemente fortes, num andar com passadas suaves; atitude lutante: deu-se no cruzamento dos fatores espaço e tempo. Com predominância nas qualidades de foco direto (atitude direta) quanto ao espaço e de velocidade rápida quanto ao tempo, num andar com passadas rápidas e diretas; atitude indireta-flexível: deuse quando as qualidades do fator espaço foram predominantemente de qualidade multifocada, num andar para várias direçóes.

Entretanto, os grupos G1 e G2, apresentaram duas atitudes e dois ímpetos, enquanto que o grupo G3 expressou um repertório gestual com quatro atitudes e três ímpetos. Nesse contexto, os ímpetos do G1 e G2 foram os de ação na situação de condução da turma com atitude complacente e o de visão na situação de organização da aula com atitude enérgica e, de disciplina dos alunos também com a atitude enérgica.

Enquanto o grupo G3, atuando há mais de 20 anos, apresentou ímpetos de ação na situação de condução da turma com atitude complacente, ímpetos de visão na situação de organização da aula com atitude enérgica e, ímpetos de encanto e de paixão na situaçáo de disciplinar os alunos com as atitudes lutante e indireta/flexível respectivamente. Portanto, o grupo G3 expressou sua gestualidade ampliada tanto referente às atitudes quanto aos impulsos na gestão da classe em relação aos demais grupos que estão no início de sua trajetória profissional.

Por fim: na situação de condução da turma todos os grupos apresentaram ímpeto de ação com uma atitude complacente ${ }^{7}$. $\mathrm{Na}$ situação de organizaçáo da aula todos os grupos apresentaram o ímpeto de visão com uma atitude enérgica ${ }^{7}$. Já, na Situação de disciplinar os grupos de professores G1 e G2 apresentaram o ímpeto de visão ${ }^{7}$, enquanto o grupo G3 o ímpeto foi de encanto e de paixão ${ }^{7}$. 


\section{Discussão}

A discussão desses dados não é tarefa fácil, pois, segundo Mesquita ${ }^{20}$ o enfoque dos conhecimentos relativos à teoria de Laban e suas aplicações está mais voltado a fundamentações teóricas e não às conclusóes de pesquisa em campo conforme o nosso estudo. Peso, espaço, tempo e fluxo são os fatores de movimento diante dos quais os professores adotaram uma atitude definida nas situaçóes docentes. A partir da combinação desses fatores, expressos nos modos de andar dos professores foram observados os ímpetos de movimento e as atitudes, para cada uma das três situaçóes da prática pedagógica do professor de educaçáo física relacionando com os saberes organizativos da gestáo da classe.

Apesar de não ser tarefa fácil, em sua complexidade encontramos a originalidade e relevância deste estudo, já que há nele uma exposição da gestualidade do professor e suas características importantes para $\mathrm{o}$ andamento do processo pedagógico docente.

\section{Atitude e ímpeto dos professores na situação de conduçáo da turma}

Nesse contexto, o andar dos professores para conduzir a turma apresentou-se, pela labanálise, predominantemente com velocidade de passos moderados e poucas vezes rápidos, como foi o caso dos três grupos de professores G1, G2 e G3.

Segundo $\mathrm{MAGEE}^{21}$, o padrão do andar pode ser alterado devido a patologias ou mesmo devido ao processo de envelhecimento. A professora andou sempre próxima dos alunos, tocando-os levemente nos ombros ou máos. Seus passos e passadas durante o andar para conduzir a turma foram predominantemente lentos. Mostrou-se com passadas lentas, referente ao fator tempo, e com passos arrastados, suaves, referente ao fator peso, minimizando assim a fase aérea do padrão cíclico da marcha. Como vimos, também, nesse andar, houve o contato corporal leve. A consciência do Fator Peso libera atitudes de toque firme e leve, com força ou delicadeza ${ }^{11}$. Corroborando nossos dados, os professores entraram em contato corporal com os alunos de maneira leve e com toque delicado nos ombros de seus alunos.

Isso também é bem comum no cotidiano docente do professor de educação física, a saída das quatro paredes e o distanciamento das carteiras escolares, propiciam um ambiente de maior aproximação corporal com uma interação mais suave, menos tensa, portanto atitude complacente. Ao andar para conduzir a turma os grupos de professores apresentaram ênfase numa atitude complacente, conforme LABAN ${ }^{7}$. Todos realizaram um modo de andar sem tensão durante a condução da turma. A atitude complacente deu-se num modo de andar tranquilo, vagaroso e relaxado com passadas lentas do professor, o que não quer dizer de um andar despreocupado e ou indeciso.

Os três grupos de professores apresentaram ênfase num ímpeto de ação, quando o fator fluxo esteve sem predominância no andar dos professores. No cotidiano da educação física escolar, conduzir a turma para o espaço da aula, que geralmente é afastado das salas de aula, é uma prática comum. Portanto, praticamente todos os professores vivenciam este deslocamento. Consistindo já num dos saberes experienciais organizativos produzidos na gestão da classe, que exige a organização do espaço previamente em outro ambiente.

Esse andar de condução da turma traduz uma relaçáo afetiva entre professor-aluno que ajuda na formação do aprendiz e na construção de sua relaçáo com o outro, pois é por meio do outro que o indivíduo poderá se delimitar nesse processo de construção contínuo.

A atitude complacente dos professores na conduçáo da turma torna esse momento agradável e estabelece uma relação de confiança e segurança mútua. De forma que o aluno que recebe o afeto sente-se seguro por poder estabelecer essa relaçáo com o professor e o professor que também recebe o afeto sente-se seguro por ter a aceitaçáo de seus aprendizes.

Podemos afirmar que em cada decisão estabelecida pelos professores, desde o planejamento até as açóes pedagógicas, há influência nessa relação afetiva entre professor-aluno e ela acaba se constituindo como um fator importante das relaçóes que acontecem entre os alunos e os conteúdos escolares, na mediaçáo com o docente.

A afetividade ${ }^{6}$ é uma dimensão humana relevante que se estabelece entre educador e educando. Essa relevância não minimiza a importância de outros saberes. Mas este perpassa os saberes organizativos e cognitivos e até mesmo outros saberes docentes para além dos experienciais, tais como: os saberes disciplinares, curriculares e os da ciência da educação. Os papeis sociais não são confundidos, pois a afetividade cria um ambiente com empatia, diante da construção de uma identidade respeitosa, carinhosa, rigorosa entre professor e aluno. 
Ímpeto e atitude do professor na situaçáo de organizaçáo da aula

Ao andar para organizar a aula, os grupos de professores apresentaram ênfase numa atitude controlada, ou seja, houve interrupçáo dos passos sempre que se fez necessário durante a aula. As qualidades relativas ao fator espaço podem ser exploradas ${ }^{13}$ através de caminhadas que possuem um objetivo final definido, em gestos que cortam o espaço dirigindo-se a um ponto determinado.

Para $\operatorname{LABAN}^{7}$ uma atitude é controlada ou livre quando diz respeito ao fator fluência. $\mathrm{O}$ modo de andar preferencialmente rápido, controlado e multifocado em várias direçóes resultou numa atitude enérgica e lutante. $\mathrm{Na}$ organização da aula, os três grupos de professores apresentaram um ímpeto de visão como elemento importante para manter o controle da turma devido à ênfase apresentada nos fatores de tempo, espaço e fluência.

Percebeu-se que, ao andar para organizar a aula um dos professores, do G1, expressou uma variedade de qualidades quanto aos fatores de movimento, e esses dados são corroborados por Fernandes ${ }^{19}$ ao mencionar que o movimento humano está em constante variação expressiva e que uma nova qualidade e suas combinaçóes concedem um novo arranjo às açóes corporais. Destacamos que a atitude controlada dos professores evidenciou tranquilidade e segurança ao realizar a aula.

O professor ao caminhar com determinação, com passos seguro e presença clara dos objetivos, demonstra que sabe o que deve fazer em cada momento de sua aula, que ele tem o domínio do que está acontecendo naquele espaço. $\mathrm{E}$, isso tem uma grande influência no desempenho dos alunos nas aulas, ou seja, se o professor náo tiver uma atitude controlada nâo conseguirá manter a organização da aula, por consequência os alunos não estarão motivados a participarem daquele momento.

O incentivo à aprendizagem faz parte do saber organizativo $^{6}$, que leva o docente a usar recursos e dinâmicas diferenciadas, procurando despertar a atenção dos alunos e provocar o desejo de realizálas. O uso do incentivo com elogios, gestos, cumprimentos provoca no aluno a confiança e o desejo de participar no e do trabalho docente.

Percebemos uma diferença de gênero entre o professor e a professora do G3, sujeitos com mais idade e tempo de atuaçáo, portanto mais experientes no ato docente. Os passos do professor se mostraram maiores no comprimento e com velocidade rápida do que os passos da professora. Esses resultados corroboram, pelo menos no que concerne ao avançar da idade ou mesmo experiência, como os estudos de $\operatorname{LABAN}^{7}$ em que o modo de andar pode ser realizado com passos estreitos e largos, e, com a teoria de $\mathrm{MAGEE}^{21}$ a qual estabelece uma relação de alguns parâmetros da marcha que diminuem significativamente nas mulheres em comparação com os homens: são a velocidade e o comprimento dos passos. A atitude enérgica foi predominante nos grupos G1, G2 e G3, num andar com passadas de qualidades fortes. Atitude energética dar-se num modo de andar ágil com passadas decididas e segura.

\section{Ímpeto e atitude do professor na situaçáo de disciplinar os alunos}

Ao andar para disciplinar, os professores do grupo G2 e G2 apresentaram ênfase numa atitude direta, ou seja, um andar objetivado de quem sabe exatamente aonde quer chegar e o que fazer. A atitude direta no andar do professor, evidenciada pelo andar rápido, com movimento acelerado das pernas para alcançar os alunos e manter a ordem da aula. Para $\operatorname{LABAN}^{7}$ uma atitude é direta quando diz respeito ao fator espaço. E, uma atitude direta, segundo Miranda ${ }^{13}$ pode ser reconhecida num olhar penetrante e num andar decidido. Nossos resultados da atitude do andar do professor são corroborados pelos estudos ${ }^{22,23,24}$ que demonstraram a relaçáo do ato do andar com as diferentes atitudes e ímpetos dos indivíduos.

Percebeu-se que a relação professor/aluno do grupo G3, professores que estavam atuando na escola a mais de vinte anos, diferenciaram-se dos grupos G1 e G2 que estavam no início e meio da trajetória profissional. A relação prolongada do professor com a cultura da escola coloca as relaçóes humanas num patamar de vínculos profissionais $\mathrm{e}$ afetivos diferenciados com seus alunos. Desse modo, desvelou-se um código de conduta estabelecido entre alunos e professores que tornaram essa relação singular. Os alunos demonstraram respeito à presença dos professores e bom comportamento durante quase todas as aulas, fazendo com que as mesmas geralmente fluíssem sem atos indisciplinares.

Uma dessas atitudes ainda muito constante no trabalho docente é a busca de silêncio, entendido como um ato de disciplina. E, embora esse seja um saber ${ }^{6}$ que todas as professoras mobilizam, a fim de conseguirem a disciplina da sala, o que caracteriza uma sala "bem-comportada" parece variar de uma professora para outra. Comumente, o 
"bom comportamento" é caracterizado pelo silêncio e pela realização de açóes permitidas pela docente. Para outras professoras, o "bom comportamento" está ligado às condições de diálogo entre professora e alunos e alunas.

Para Guimarães ${ }^{6}$ existem ações que buscam repreender o "mau comportamento" e produzir o silêncio, mas há outras que procuram evitá-lo, tal como as brincadeiras dirigidas. Há, especialmente em escolas com metodologias tradicionais, um predomínio da inibição do movimento do aluno. O silêncio é imposto com o uso de palavras e gestos, ou ainda por reclamaçóes, puniçóes e até suspensão ou exclusão de uma determinada atividade. Por vezes a "solicitaçáo" do silêncio parte dos próprios alunos para que a atividade não seja prejudicada, ou mesmo para que a professora não necessite realizar intervençóes, muitas vezes punitivas.

Nas situaçóes da aula desveladas neste estudo os pedidos/imposições não deixaram de existir, mas de fato náo constituíram os ímpetos nas atitudes pedagógicas, pois como foi dito um código de conduta estava estabelecido. Porém a gestualidade, em especial o andar, se configurou como saber docente organizativo neste aspecto da gestão da classe. Um andar mais decidido, acompanhado de um olhar mais firme inibia atitudes indisciplinares que poderiam ou já estavam prejudicando a atividade.

Na situação de disciplinar os alunos o grupo G3 apresentou um ímpeto de encanto e náo de visão como nos demais grupos. Isso porque ao andar durante a aula para disciplinar os alunos, o grupo G3 demonstrou uma relação diferenciada com os alunos em relação ao fator tempo pela labanálise ${ }^{7}$. Esse grupo manteve uma relação com o fator tempo de maneira latente, ou seja, sem ênfase nem alteraçóes nas velocidades do andar caracterizando assim seu ímpeto de encanto, conforme LABAN ${ }^{7}$.

$\mathrm{O}$ fato de possuírem um andar decidido e o olhar penetrante evidencia que os professores sabiam o que precisavam mediar e que estavam seguros de como deveriam fazer isso. Isso muito tem a ver com a afetividade que surge na situação de condução, se o professor tem um vínculo com o aluno que vai além do ensinar, ele o conhece mais profundamente. Deste modo, tendo um vínculo de confiança e respeito mútuo, o professor sentirá mais seguro ao mediar a situação de indisciplina.

Assim, se a atitude do professor não for direta $\mathrm{e}$ decisiva nos momentos de indisciplina da turma, o que resulta numa atitude lutante, o professor estará demonstrando intimidação, medo e se comunicará com seus alunos de forma defensiva, e não será respeitado pelos alunos.

Neste estudo investigamos aspectos relativos à gestualidade na atuação do professor de educação física em escolas públicas da cidade de João Pessoa/ Paraíba. Este aspecto limitou-se a verificar qualidades atitudinais e ímpetos da ação docente que se manifestaram durante $o$ ato de andar do professor. A identificação das nuances das qualidades no ato de andar inerente às atuaçóes de cada professor, foi evidenciada pelas combinaçóes expressas, com predominância ou sem predominância, dos quatro fatores de movimento: fluxo, espaço, peso e tempo. Os três grupos de professores, desta forma, especificaram algumas particularidades em seu repertório individual de gestão da classe para organizar um ambiente propício para a aprendizagem.

Conclui-se que, dentre as possibilidades de combinação entre os quatro fatores de movimento peso-fluxo-espaço-tempo - observou-se atitudes e ímpetos comuns e ou diferenciados aos três grupos de professores. Os ímpetos e atitudes comuns ao G1, G2 e G3 observaram-se na gestão da classe quanto à situação de condução da turma e na organização da aula, no entanto, houve uma combinação diferenciada no repertório gestual do grupo G3, ao apresentar uma polaridade tanto no fator tempo quanto no fator espaço o que consequentemente desvelou respectivamente os ímpetos de encanto e de paixão nos professores do grupo G3. Tal gradação contínua entre os dois polos dos fatores de movimento é corroborado com a teoria de Laban. O estudo demonstrou que houve na gestão da classe do grupo G3 um repertório gestual ampliado preferencialmente na situação disciplinar. Portanto, há uma forte indicação de ampliação e domínio do espaço e do tempo na gestualidade de professores com uma trajetória acima de vinte anos de atuação na área de educação física escolar. Novas pesquisas são necessárias para investigar a gestualidade na atuação do professor de educação física e de treinadores. 


\section{Notas}

a. O texto foi originalmente publicado como: Tardif M, Lessard C, Lahaye L. Os professores face ao saber: esboço de uma problemática do saber docente. Teor Educ. 1991;(4):215-233.

\section{Abstract}

Gestural impetuses and knowledges of class management in physical education classes

The objective of this study was to identify the following as the pedagogical attitudes are related to the gestural impulses and how they are shown on the floor of the teacher during the management class. Initially we emphasize the specificity of Physical Education in relation to his classroom, which takes place in different spaces. Within this space many situations happen to be intermediated by the teacher, such as: driving class for space class; the organization of didactic teaching materials and students; and the act of discipline, on which delimit our analytical look for labanálise. We take qualitative research of ethnographic type to analyze the teacher's walking modes during Physical Education class. The subjects were six teachers of elementary school physical education, public network of the city of João Pessoa/PB. To observe classes use a protocol of observation and records in field diary. The floor of teachers to lead the class presented itself, by Labanálise predominantly with moderate speed and rarely quick steps, as was the case of the three groups of teachers $\mathrm{G} 1, \mathrm{G} 2$ and $\mathrm{G} 3$. While walking to organize the class, teachers groups had controlled emphasis on attitude, that is, there was an interruption of the steps whenever it was necessary during class. While walking to discipline, $\mathrm{G} 2$ and $\mathrm{G} 2$ teachers presented emphasis on direct action, i.e. an objectified floor. The three groups of teachers thus specify some peculiarities in their individual repertoire of class management to organize an environment conducive to learning.

KEYWORD: Teacher; Walking; Labanálise; Gestures.

\section{Referências}

1. Both J, Nascimento JV. Intervenção profissional na Educaçáo Física escolar: consideraçóes sobre o trabalho docente. Mov. 2009;15(2):169-86.

2. Gauthier C, Malo A, Simard D, Desbiens JF, Martineau S. Por uma teoria da pedagogia. Ijuí: Unijuí; 1998.

3. Farias GO, Nascimento JV, Graça A, Batista PMF. Crenças e expectativas constituídas ao longo da carreira docente em educação física. Rev Educ Fís UEM. 2011;22(4):497-509.

4. Gomes-da-Silva PN. O jogo da cultura e a cultura do jogo: por uma semiótica da corporeidade. João Pessoa: Editora Universitária da UFPB; 2011.

5. Tardif M. Saberes docentes e formação profissional. 4a ed. Rio de Janeiro: Vozes; 2002.

6. 6. Guimarães ODS. Saberes docentes mobilizados na dinâmica do trabalho docente: um olhar a partir do ensino fundamental [dissertação]. Recife (PE): Universidade Federal de Pernambuco; 2004.

7. Laban R. Domínio do movimento. 5a ed. São Paulo: Summus; 1978.

8. Gomes-da-Silva E, Sant'Agostino LHF, Betti M. Expressão corporal e linguagem na Educação Física: uma perspectiva semiótica. Rev Mackenzie Educ Fís Esporte. 2005;4(4):29-38.

9. Freire JB, Scaglia AJ. Educação como prática corporal. São Paulo: Scipione; 2010.

10. Brasil. Ministério da Educação. Base Nacional Comum Curricular [Internet]. Brasília, DF: Ministério da Educação; 2016 [citado 18 ago 2016]. Disponível em: http://basenacionalcomum.mec.gov.br

11. Gomes-da-Silva PN, Cavalcanti KB, Hildebrandt R. A poética dos gestos dos jogadores. Rev Bras Cienc Esporte. 2006;27(2):105-19.

12. Santaella L. O que é semiótica. São Paulo: Brasiliense; 2007.

13. Miranda R. O movimento expressivo. Brasília, DF: Funarte; 1980. 
14. Mauss M. Sociologia e antropologia. São Paulo: Cosac Naify; 2003.

15. Brandão CR, Streck DR, organizadores. Pesquisa participante: a partilha do saber. São Paulo: Ideias e Letras; 2006.

16. Costa SB. O andar como expressão da atitude pedagógica do professor de educação física [dissertação]. Recife (PE): Universidade de Pernambuco; 2010.

17. Mommensohn M, Petrella P, organizadores. Reflexóes sobre Laban, o mestre do movimento. São Paulo: Summus; 2006.

18. Lacava MCP. Você vai viver o que você vai viver: reflexóes sobre a arte da improvisaçáo de movimentos na dança. In: Mommensohn M, Petrella P, organizadores. Reflexóes sobre Laban, o mestre do movimento. São Paulo: Summus; 2006.

19. Fernandes C. Corpo em movimento: o sistema Laban-Bartenieff na formação e pesquisa em artes cênicas. São Paulo: Annablume; 2006.

20. Mesquita RM. Comunicação não-verbal: atuação profissional e percepção da psicodinâmica do movimento expressivo [tese]. São Paulo (SP): Universidade de São Paulo; 1997.

21. Magee DJ. Avaliação musculoesquelética. 5a ed. Barueri: Manole; 2010.

22. Montepare JM, Goldstein SB, Clausen A. The identification of emotions from gait information. J Nonverbal Behav. 1987;11(1):33-42.

23. Asendorpf J, Wallbott HG. Contributions of the German "Expression Psychology” to nonverbal communication research. J Nonverbal Behav. 1982;6(3):135-47.

24. Spode E, Clezar R. Reeducação afetiva: uma proposta para a integração dos educandos com dificuldade de aprendizagem envolvendo a biodanza. Porto Alegre: Imagens da Terra; 2006.

ENDEREÇO

Sandra Barbosa da Costa

Castelo Branco, Campus I - 58051-900

João Pessoa - BRASIL

e-mail: sbcufpb@gmail.com
Recebido para publicação: 18/08/2016

$1^{\text {a }}$. Revisão: 05/10/2017

$2^{\mathrm{a}}$. Revisão: 28/05/2018

Aceito: 11/07/2018 